\title{
Decreased Perception of High Frequency Sound in Severe Obstructive Sleep Apnea
}

\author{
T. VORLOVÁ ${ }^{1}$, O. DLOUHÁ ${ }^{2}$, D. KEMLINK ${ }^{1}$, K. ŠONKA ${ }^{1}$ \\ ${ }^{1}$ Department of Neurology and Center for Clinical Neuroscience, First Faculty of Medicine, Charles \\ University and General University Hospital, Prague, Czech Republic, ${ }^{2}$ Department of Phoniatrics, \\ First Faculty of Medicine, Charles University and General University Hospital, Prague, Czech \\ Republic
}

Received August 21, 2015

Accepted April 15, 2016

On-line August 19, 2016

\section{Summary}

Obstructive sleep apnea (OSA) is characterized by recurrent episodes of upper airway obstruction during sleep, which is manifested by apnea or hypopnea. Decreased blood oxygen saturation, changes in heart rate, fluctuations in brain perfusion, changes in intracranial pressure, snoring and vibration are factors that may potentially affect hearing in patients with OSA. The aim of the present study was to test the hypothesis that hearing is affected in OSA. 43 males aged 34-74 years (mean 48.2) with suspected sleep-disordered breathing without other comorbidity or medication that may affect sleep or hearing were included. Nocturnal polysomnography, pure tone audiometry (PTA), transient evoked otoacoustic emissions (TEOAE) and brainstem auditory evoked potentials (BAEP) were evaluated. The severity of OSA was indicated by the number of apneas and hypopneas per hour of sleep (apnoe/hypopnoe index - AHI). OSA ( $\mathrm{AHI} \geq 5$ ) was detected in 28 patients by polysomnography. Mild OSA (AHI 5-15) was confirmed in 11 patients, severe OSA (AHI $\geq 30$ ) in 17 patients. Simple snoring $(\mathrm{AHI}<5)$ was diagnosed in 15 males. In patients suffering from severe OSA, tone audiometry demonstrated higher auditory threshold at frequencies of 4000 and $8000 \mathrm{~Hz}$ than in patients with $\mathrm{AHI}<15$ $(p<0.005)$. Auditory threshold values correlated with age in all groups. At a frequency of $8000 \mathrm{~Hz}$, auditory threshold additionally correlated with BMI, AHI, oxygen desaturation index and decreased oxygen saturation. No differences were detected in TEOAE and BAEP between subjects with OSA and snoring. PTA and TEOAE decreased with increasing age. The present results show decreased perception of high frequency sound in severe OSA.

\section{Key words}

Obstructive sleep apnea - Pure tone audiometry - Transient evoked otoacoustic emissions - Organ of Corti • Brainstem auditory evoked potential

\section{Corresponding author}

K. Šonka, Department of Neurology and Center for Clinical Neuroscience, First Faculty of Medicine, Charles University and General University Hospital, Kateřinská 30, 12821 Prague 2, Czech Republic. Fax: +420224922678 . E-mail: ksonka@lf1.cuni.cz

\section{Introduction}

Obstructive sleep apnea (OSA) is characterized by recurrent episodes of complete or partial upper airway obstruction during sleep (ICSD-2 2005). Excessive fluctuations in intrathoracic pressure, decreased blood oxygen saturation, tissue hypercapnia, changes in heart rate and changes in intracranial pressure result from apnea or hypopnea. OSA is considered a risk factor for cardiovascular disease (Marin et al. 2005, Gilat et al. 2014, Gami et al. 2013), and its influence on the development of arterial pulmonary hypertension, cardiac arrhythmias, atherosclerosis and type 2 diabetes has been demonstrated (Drager et al. 2010, Namtvedt et al. 2013, Manin et al. 2015, Kendzerska et al. 2014, Dumitrascu et al. 2013). Cognitive dysfunction dependent on the severity of OSA has been documented, as well as structural brain changes in OSA compared to control 
subjects (Canessa et al. 2011, Torelli et al. 2011).

It may be hypothesized that hearing is negatively affected in OSA, as the peripheral auditory perceptual organ (inner ear), vestibulocochlear nerve and central nuclei and pathways are intimately connected with or are a part of the brain, and share a common blood supply. The aim of the present study was to investigate potential auditory dysfunction in OSA at the level of the organ of Corti, the auditory pathway and the brainstem auditory areas. To fulfill this objective, the following three tests were employed.

1. Pure tone audiometry (PTA) determines the auditory threshold after standard frequency stimuli.

2. Transient evoked otoacoustic emissions (TEOAE) are sounds given off by the inner ear when the cochlea is stimulated by a sound (click). TEOAE evaluates preneuronal auditory transmission and does not reflect the ability to transmit sound from the hair cells centrally (Kemp 2010, Reichenbach et al. 2012).

3. Brainstem auditory evoked potentials (BAEP) measure the function of the auditory nerve and auditory pathways in the brainstem (Evans 2012).

\section{Methods}

\section{Study participants}

The study was conducted from 2010-2013 at a tertiary university hospital in patients referred for suspected sleep apnea. All patients had a history of snoring, were subjected to standard physical, neurological and ear, nose and throat (ENT) examinations, as well as nocturnal polysomnography and ultrasound examination of the carotid arteries. Additionally, the following inclusion criteria were imposed: a) male gender, b) 18 years of age and over, c) generally good health, d) absence of sleep disorders (restless legs syndrome, periodic limb movements in sleep, insomnia, narcolepsy, parasomnias, circadian rhythm disorder), e) absence psychiatric disorders (including anxiety disorders), f) no previous or concurrent use of medications that may affect hearing, sleep or breathing while asleep (e.g. statins, diuretics, chemotherapeutic agents, benzodiazepines), g) normal findings on physical, neurological and ENT examinations, including negative history for any serious internal diseases (e.g. disorders of extrapyramidal system and cerebellum, migraine, cluster headache, demyelinating disease, autoimmune disease, tumor or arteriovenous malformation, stroke, epilepsy, anemia, diabetes mellitus, decompensated hypertension, ischemic heart disease, head injury with loss of consciousness, labyrinth contusion, fracture of the pyramid, Meniere's disease, vestibular schwannoma or other intracranial tumors, peripheral vestibulopathy, vertigo, previously diagnosed deafness or hearing loss), h) the absence of atherosclerotic changes in the carotid artery and i) written informed consent to participate in the study. The study included 43 consecutively recruited males aged 34-74 years (mean 48.2 $\pm 8.9 \mathrm{SD}$ ).

\section{Examination}

1. Polysomnography (PSG) was performed by means of a BrainLab 3.1 (Schwarzer, Germany). The PSG recording included four electroencephalographic leads (C3-A2, C4-A1, O1-A2, O2-A1), two electrooculographic leads (E1-M2, E2-M2) and chin and bilateral anterior tibialis surface electromyograms, one electrocardiographic lead, respiratory sounds, nasal airflow (thermistors), thoracic and abdominal movements (piezoelectric belts), finger probe oximetry and body position record. Sleep was scored according to Rechtschaffen and Kales criteria (Rechtschaffen and Kales 1968). Apnea was defined as complete airflow cessation $\geq 10 \mathrm{~s}$ and hypopnea as $50 \%$ or greater reduction of air inflow leading to $3 \%$ or greater oxyhemoglobin desaturation of $\geq 10 \mathrm{~s}$ duration. Periodic limb movements (PLM) were defined according to WASM standards (Zucconi et al. 2006). A PLM index (number of PLM per hour of sleep) smaller than 10 was selected as an inclusion criterion. All patients were allowed to sleep from 22:00 to 6:00 (polysomnography duration, time in bed). For statistical purposes, the following parameters were processed: apnea/hypopnea index (AHI - number of apneas and hypopneas per hour of sleep), oxygen desaturation index (ODI - number of saturation drops by $3 \%$ and more per hour) and percent of time with oxygen saturation below $90 \%$ (T90).

2. Ultrasound examination of the carotid arteries was performed on a Toshiba 4D Aplio 300 device (Toshiba Medical Systems, Japan). Potential atherosclerotic changes in the carotid arteries were assessed by evaluating the intimal-medial thickness of the bilateral common carotid arteries. An intimal-medial thickness of less than $0.82 \mathrm{~mm}$ was imposed as an inclusion criterion, according to Czech neurosonological standard (Škoda et al. 2002).

3. PTA was examined by a two-channel audiometer Madsen Orbiter 922 (GN Otometrics, Taastrup, Denmark). Stimulus step was $5 \mathrm{~dB}$. The 
auditory threshold was measured at frequencies of $125-8000 \mathrm{~Hz}$, according to international standards. Frequencies of 1000, 2000, 4000 and $8000 \mathrm{~Hz}$ were statistically evaluated. According to the same standards, the normal auditory threshold is in the range of $0-25 \mathrm{~dB}$ (Mathers et al. 2000).

4. TEOAE were measured by an ILO 88 instrument (Otodynamics Ltd., Hatfield, UK) placed in the external auditory canal. The probe emits a wide frequency spectrum stimulus and detects a response from the organ of Corti. A range of signals emitted by the external hair cells of the organ of Corti were registered, up to frequencies of $6000 \mathrm{~Hz}$ and frequencies of 1000 , 2000, 4000, and $6000 \mathrm{~Hz}$ were used in statistical analyses. The duration of the electric pulse applied to the transducer was $80 \mu$ s using a nonlinear stimulus mode. The number of stimuli employed in the default condition was 260 transients for each ear. Clicks elicit broadspectrum responses that are most robust in the midfrequency region, likely reflecting the fact that middle ear transfer is most sensitive in the range of 1000-3000 Hz. TEOAE were evaluated with respect to reproducibility (in \%) and amplitude of the signal to noise ratio $(\mathrm{S} / \mathrm{N})$. $\mathrm{S} / \mathrm{N}$ is defined as the ratio of signal power to the noise power, expressed in decibels. A ratio higher than 1:1 (greater than $0 \mathrm{~dB}$ ) indicates more signal than noise, reproducible response is evident at a $\mathrm{S} / \mathrm{N}$ of $3 \mathrm{~dB}$ or more. The result is expressed as the proportion of clicks causing otoacoustic emissions. Normally TEOAE have a value in the range of $75-100 \%$, using an objective criterion based on an entire reproducibility score greater than $70 \%$ (Robinette and Glattke 2002).

5. BAEP was examined with a Dantec Keypoint device (Natus Medical Inc., Pleasanton, CA). The time window was $10 \mathrm{~s}$, the stimulus was an acoustic click created by a pulse of $0.1 \mathrm{~ms}$, and the stimulus was presented 2,000 times for each recording trial. BAEPs were examined using a monoaural rarefaction click stimulation of $69 \mathrm{~dB}$ sensation level intensity and $10 \mathrm{~Hz}$ frequency. We evaluated wave peak latency I (normal $<2.05 \mathrm{~ms}$ ), III (normal $<4.06 \mathrm{~ms}$ ), $\mathrm{V}$ (normal $<6.21 \mathrm{~ms}$ ) and interpeak latencies I-III (normal $<2.52 \mathrm{~ms}$ ), III-V (normal $<2.36 \mathrm{~ms}$ ) and I-V (normal $<4.61 \mathrm{~ms}$ ). Normal values were determined from the examinations performed at our institution in healthy volunteer subjects (30 males, 30 females) (Jech and Růžička 1996).

PTA, TEOAE and BAEP were examined in the afternoon.

\section{Statistical analysis}

We compared the results of tone audiometry, TEOAE and BAEP between groups with varying severity of OSA expressed by AHI, including adjustment for body mass index (BMI), which was conducted using ANCOVA. We conducted the following comparisons: a) $\mathrm{AHI} \geq 30$ vs. $\mathrm{AHI}<5$, b) $\mathrm{AHI} 5-15$ vs. $\mathrm{AHI}<5$, c) $\mathrm{AHI} \geq 30$ vs. AHI 5-15, and d) $\mathrm{AHI} \geq 30$ vs. $\mathrm{AHI}<15$. None of the parameters were normally distributed. For comparisons between two groups, the Mann-Whitney$\mathrm{U}$ test was used, for comparison between three groups the Kruskal-Wallis test. When performing ANCOVA the residuals were found to be normally distributed, thus despite the abnormal distribution of raw data, these results are interpretable. All tests were performed using the STATISTICA 12 software package (StatSoft, Inc., Tulsa, OK).

The study was approved by Ethical Committee of the General University Hospital in Prague.

\section{Results}

OSA $\quad(\mathrm{AHI} \geq 5)$ was detected by polysomnography in 28 patients, of which 11 patients were diagnosed with mild OSA (AHI 5-15) and 17 patients with severe $\mathrm{OSA}(\mathrm{AHI} \geq 30)$. None of the patients were diagnosed with moderate OSA (AHI 15-30). Sleep-disordered breathing was not detected in 15 patients, who were diagnosed with the simple snoring $(\mathrm{AHI}<5)$. Table 1 shows study participants grouped according to severity of OSA, expressed by AHI. ODI statistically differed between groups. No difference in age was detected between OSA positive patients and those in whom OSA was not observed. Patients diagnosed with severe OSA demonstrated higher average BMI than patients with mild OSA and controls.

PTA demonstrated significantly higher auditory thresholds in patients with severe OSA than all the other subjects examined at the frequencies of 4000 and 8000 $\mathrm{Hz}$ (Table 2), and the difference remained significant when correcting for BMI using ANCOVA at the frequency of $8000 \mathrm{~Hz}$. No difference was detected between groups with mild OSA and simple snoring. PTA values correlated with age, and at a frequency of $8000 \mathrm{~Hz}$, with all examined parameters (i.e. age, BMI, AHI, ODI and T90; Table 3). Correlation between AHI and PTA at 4000 and $8000 \mathrm{~Hz}$ is illustrated in Figures 1 and 2. 
Table 1. Patient demographic information by AHI classification.

\begin{tabular}{|c|c|c|c|c|}
\hline & \multirow{2}{*}{$\begin{array}{c}\text { Normal breathing } \\
\text { during sleep } \\
(\mathrm{AHI}<5) \\
\end{array}$} & \multicolumn{2}{|c|}{ OSA $(\mathrm{AHI} \geq 5)$} & \multirow{2}{*}{$\begin{array}{c}\text { P-value } \\
\text { AHI }<15 \text { vs. AHI } \geq 30 \\
(\text { ANCOVA) }\end{array}$} \\
\hline & & AHI 5-15 & $\mathbf{A H I} \geq \mathbf{3 0}$ & \\
\hline Number & 15 & 11 & 17 & \\
\hline Age (years) & $47.3 \pm 8.0$ & $46.4 \pm 9.2$ & $50.8 \pm 10.2$ & NS \\
\hline$B M I\left(\mathrm{~kg} / \mathrm{m}^{2}\right)$ & $26.8 \pm 1.9$ & $28.3 \pm 3.1$ & $33.4 \pm 5.6^{*}$ & $<0.001$ \\
\hline$A H I$ & $1.9 \pm 1.5$ & $8.4 \pm 3.0$ & $60.5 \pm 31.9^{*}$ & $<0.001$ \\
\hline$O D I$ & $2.9 \pm 2.8$ & $9.5 \pm 3.6$ & $60.3 \pm 29.7 *$ & $<0.001$ \\
\hline$T 90$ & $0.1 \pm 0.5$ & $0 \pm 0.1$ & $0.4 \pm 0.4^{*}$ & $<0.001$ \\
\hline
\end{tabular}

Data are mean \pm SD. OSA, obstructive sleep apnea; BMI, body mass index; AHI, apnea-hypopnea-index; ODI, oxygen desaturation index; T90, proportion of time peripheral blood oxygen saturation below $90 \%$ relative to time in bed; NS, not significant. Significantly different means are indicated by asterisk.

Table 2. Tone audiometry in groups by AHI classification.

\begin{tabular}{|c|c|c|c|c|}
\hline \multirow{2}{*}{ Tone audiometry } & \multirow{2}{*}{$\begin{array}{c}\text { Normal breathing } \\
\text { during sleep } \\
(\mathrm{AHI}<5)\end{array}$} & \multicolumn{2}{|c|}{ OSA $(\mathrm{AHI} \geq 5)$} & \multirow{2}{*}{$\begin{array}{c}\text { P-value } \\
\text { AHI }<15 \text { vs. AHI } \geq 30 \\
\text { (ANOVA) }\end{array}$} \\
\hline & & AHI 5-15 & $\mathbf{A H I} \geq \mathbf{3 0}$ & \\
\hline $1000 \mathrm{~Hz}$ & $11.33 \pm 5.74$ & $10.55 \pm 1.04$ & $11.47 \pm 4.24$ & NS \\
\hline $2000 \mathrm{~Hz}$ & $10.77 \pm 3.65$ & $10.73 \pm 1.67$ & $15.59 \pm 9.66$ & NS \\
\hline $4000 \mathrm{~Hz}$ & $12.73 \pm 6.55$ & $14.55 \pm 9.34$ & $29.71 \pm 19.72 *$ & $<0.005$ \\
\hline $8000 \mathrm{~Hz}$ & $11.33 \pm 4.43$ & $11.82 \pm 4.01$ & $33.24 \pm 20.99^{*}$ & $<0.005$ \\
\hline
\end{tabular}

Data are mean \pm SD. AHI, apnea-hypopnea-index; Hz, Hertz; NS, not significant. Significantly different means are indicated by asterisk.

Table 3. Tone audiometry: correlation with age, BMI, T90, ODI and AHI (Spearman correlation).

\begin{tabular}{|c|c|c|c|c|}
\hline & $1000 \mathrm{~Hz}$ & $2000 \mathrm{~Hz}$ & $4000 \mathrm{~Hz}$ & $8000 \mathrm{~Hz}$ \\
\hline \multirow[t]{2}{*}{ Age } & 0.4159 & 0.5470 & 0.4084 & 0.5007 \\
\hline & $p=0.006$ & $\mathrm{p}<\mathbf{0 . 0 0 1}$ & $p=0.007$ & $p=0.001$ \\
\hline \multirow[t]{2}{*}{$B M I$} & 0.3668 & $\mathbf{0 . 3 1 0 7}$ & 0.4955 & 0.5054 \\
\hline & $p=0.016$ & $\mathbf{p}=\mathbf{0 . 0 3 7}$ & $p=0.001$ & $p=0.001$ \\
\hline \multirow[t]{2}{*}{$T 90$} & 0.1744 & 0.1871 & 0.3259 & 0.4681 \\
\hline & $\mathrm{p}=0.263$ & $\mathrm{p}=0.230$ & $p=0.033$ & $p=0.002$ \\
\hline \multirow[t]{2}{*}{$O D I$} & 0.1129 & 0.2277 & 0.3780 & 0.4521 \\
\hline & $\mathrm{p}=0.471$ & $\mathrm{p}=0.142$ & $p=0.012$ & $p=0.002$ \\
\hline \multirow[t]{2}{*}{$A H I$} & 0.1530 & 0.2681 & 0.3941 & 0.4607 \\
\hline & $\mathrm{p}=0.327$ & $\mathrm{p}=0.082$ & $p=0.009$ & $p=0.002$ \\
\hline
\end{tabular}

BMI, body mass index; T90, proportion of time peripheral blood oxygen saturation below $90 \%$ relative to time in bed; ODI, oxygen desaturation index; AHI, apnea-hypopnea-index; Hz, Hertz. Statistically significant correlations are given in bold. 


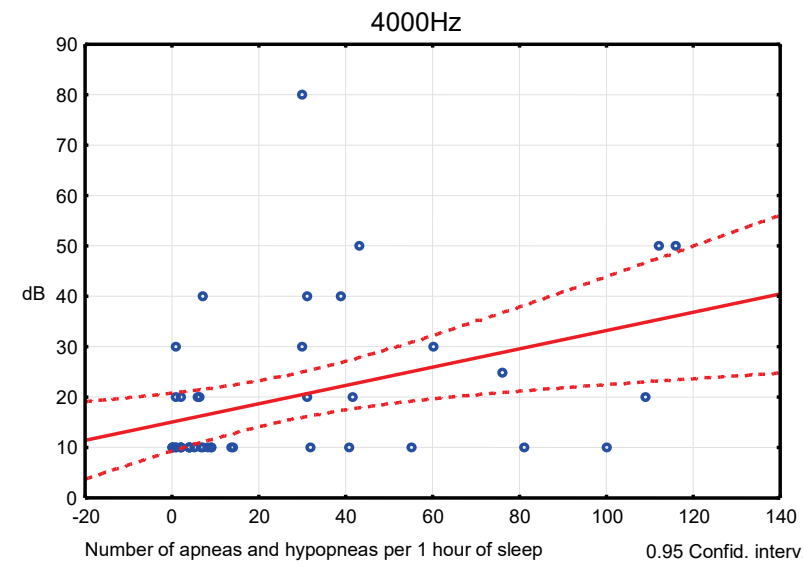

Fig. 1. Correlation between AHI and PTA at frequency $4000 \mathrm{~Hz}$, correlated with age (Spearman correlation statistic). AHI, apnea/hypopnea index; PTA, pure tone audiometry; dB, decibel; $\mathrm{Hz}$, Hertz.

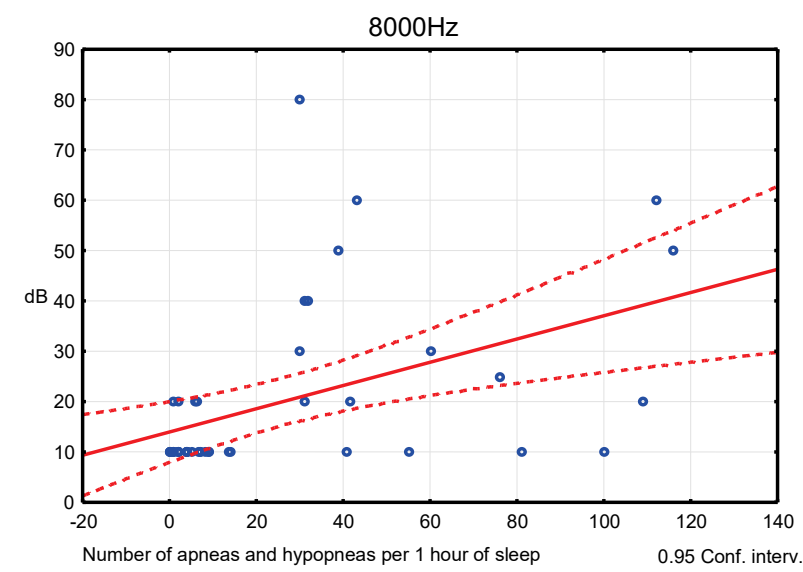

Fig. 2. Correlation between AHI and PTA at frequency $8000 \mathrm{~Hz}$, correlated with age, body mass index, oxygen desaturation index, oxygen saturation below $90 \%$ (Spearman correlation statistic). AHI, apnea/hypopnea index; PTA, pure tone audiometry; $\mathrm{dB}$, decibel; $\mathrm{Hz}$, Hertz.

Table 4. TEOAE in groups by AHI classification (mean values and standard deviations in percent).

\begin{tabular}{|c|c|c|c|c|c|}
\hline \multirow{2}{*}{ TEOAE } & & \multirow{2}{*}{$\begin{array}{c}\text { Normal breathing } \\
\text { during sleep } \\
(\mathrm{AHI}<5) \\
\end{array}$} & \multicolumn{2}{|c|}{ OSA $(\mathrm{AHI} \geq 5)$} & \multirow{2}{*}{$\begin{array}{c}\text { P-value } \\
\text { AHI }<15 \text { vs. AHI }>30 \\
\text { (ANOVA) }\end{array}$} \\
\hline & & & AHI 5-15 & $\mathbf{A H I}>\mathbf{3 0}$ & \\
\hline \multirow[t]{2}{*}{$1000 \mathrm{~Hz}$} & $L$ & $66.5 \pm 41.7$ & $82.7 \pm 28.3$ & $75.6 \pm 32.1$ & NS \\
\hline & $R$ & $73.8 \pm 39.3$ & $87.7 \pm 12.1$ & $83.5 \pm 23.4$ & NS \\
\hline \multirow[t]{2}{*}{$2000 \mathrm{~Hz}$} & $L$ & $77.7 \pm 30.6$ & $86.5 \pm 19.4$ & $71.7 \pm 31.5$ & NS \\
\hline & $R$ & $86.7 \pm 16.1$ & $91.7 \pm 10.9$ & $71.6 \pm 33.0$ & NS \\
\hline \multirow[t]{2}{*}{$4000 \mathrm{~Hz}$} & $L$ & $24.3 \pm 36.3$ & $29.5 \pm 41.6$ & $27.8 \pm 36.1$ & NS \\
\hline & $R$ & $40.5 \pm 40.5$ & $45.5 \pm 43.9$ & $23.9 \pm 35.2$ & NS \\
\hline \multirow[t]{2}{*}{$6000 \mathrm{~Hz}$} & $L$ & $4.8 \pm 18.6$ & $0.0 \pm 0.0$ & $0.0 \pm 0.0$ & NS \\
\hline & $R$ & $0.0 \pm 0.0$ & $8.4 \pm 27.7$ & $4.1 \pm 17.0$ & NS \\
\hline
\end{tabular}

Data are mean \pm SD. TEOAE, transiently evoked otoacoustic emissions; OSA, obstructive sleep apnea; SD, standard deviation; AHI, apnea-hypopnea-index; Hz, Hertz; L, left; R, right; NS, not significant.

Table 5. TEOAE: correlation with age, BMI, T90, ODI and AHI (Spearman correlation).

\begin{tabular}{lllllll}
\hline TEOAE & & Age & BMI & AHI & ODI & T90 \\
\hline \multirow{2}{*}{$1000 \mathrm{~Hz}$} & $L$ & $\mathbf{- 0 . 4 0 2}$ & -0.075 & 0.134 & 0.077 & 0.022 \\
& $R$ & $\mathbf{- 0 . 4 5 0}$ & -0.251 & -0.097 & -0.137 & -0.235 \\
$2000 \mathrm{~Hz}$ & $L$ & $\mathbf{- 0 . 3 8 3}$ & -0.137 & -0.167 & -0.219 & -0.225 \\
& $R$ & $\mathbf{- 0 . 3 8 0}$ & -0.197 & -0.150 & -0.189 & -0.204 \\
$4000 \mathrm{~Hz}$ & $L$ & $\mathbf{- 0 . 0 7 1}$ & 0.012 & 0.069 & 0.066 & 0.016 \\
& $R$ & -0.351 & -0.233 & -0.141 & -0.138 & -0.185 \\
$6000 \mathrm{~Hz}$ & $L$ & -0.137 & -0.187 & -0.249 & -0.255 & -0.184 \\
& $R$ & 0.106 & 0.086 & 0.132 & 0.061 & 0.126 \\
\hline
\end{tabular}

TEOAE, transiently evoked otoacoustic emissions; BMI, body mass index; T90, proportion of time peripheral blood oxygen saturation below $90 \%$ relative to time in bed; ODI, oxygen desaturation index; AHI, apnea-hypopnea-index; L, left; R, right; Hz, Hertz. Statistically significant correlations are given in bold $(p<0.05)$. 
No significant differences were detected in TEOAE (including S/N, Table 4) and BAEP between patients with severe OSA and patients with $\mathrm{AHI}<15$.

PTA and TEOAE decreased with increasing age: PTA left - correlation $r=-0.4996, p=0.001$; PTA right correlation $\mathrm{r}=-0.4862, \mathrm{p}=0.002 ;$ TEOAE left correlation $\mathrm{r}=-0.3389, \mathrm{p}=0.026$; TEOAE right correlation $r=-0.3409, p=0.025$ (correlations of age with each TEOAE frequencies 1000, 2000, 4000 and $6000 \mathrm{~Hz}$ are displayed in Table 5). PTA (frequencies 1000-4000 $\mathrm{Hz}$ ) and TEOAE correlate in whole patients group (not in OSA severity subgroups). BAEP showed no age-related changes.

\section{Discussion}

In the present study, we show that the auditory threshold is increased while listening to sounds of higher frequency in patients with severe OSA, and that this increase correlates with the severity of OSA. We did not observe any change in TEOAE and BAEP due to OSA. A few studies have examined the influence of OSA on hearing, however their results are not conclusive (Hwang et al. 2011, Casale et al. 2012, Kotterba and Rasche 1996, Cimino et al. 1995, Schlegel and Urban 1999, Paquereau et al. 1994, Urban et al. 1996, Mosko et al. 1981) perhaps due to differing patient characteristics.

PTA in severe OSA was measured by Casale $e t$ al. (2012). While they reported that patients with severe OSA had a higher auditory threshold when averaging stimulation results from 5 tones between $250-4000 \mathrm{~Hz}$, in examining individual frequencies, the auditory threshold was higher in only their highest frequency. Thus, our results are in agreement with this study. PTA results in mild and moderate OSA were normal as in our study, as well as in a study by Hwang et al. (2011), which included 34 subjects.

TEOAE in OSA has only been assessed by Casale et al. (2012). In contrast to the present study, they reported less reproducibility in patients with severe OSA. TEOAE methodology and patient selection were virtually the same as in the present work. The differing results may be explained by differences in patient age, and more importantly, by the stringent selection criteria of patients in our study. In this respect, exclusion of atherosclerotic disease by ultrasound in the present study was particularly important. Additionally, in contrast to other studies, we included only male subjects. But the effect of gender on TEOAE results remains the subject of debate
(McFadden 1993).

BAEP in OSA has been evaluated in several studies. In contrast to our results, Casale et al. (2012) reported prolonged mean latencies of waves I, III and V in a group of OSA patients in comparison to healthy volunteers. Kotterba and Rasche (1996) evaluated BAEP in 20 OSA patients (17 men, 3 women; mean age 54 years) and reported prolonged latency in wave I and intervals $\mathrm{I}-\mathrm{V}$ in comparison to controls. The BAEP results reported by Kotterba and Rasche (1996) and Casale et al. (2012) are unique, as in addition to the present study, normal BAEP in OSA has been reported by Cimino et al. (1995), Schlegel and Urban (1999), Paquereau et al. (1994), Urban et al. (1996) and Mosko et al. (1981). Differences in BAEP results between the current study and those by Kotterba and Rasche (1996) and Casale et al. (2012) may also be explained by our rigorous inclusion criteria, which excluded patients with hearing impairment of other etiology.

Increased auditory threshold at higher frequencies as determined by PTA and the absence of abnormalities on TEOAE and BAEP examinations in patients with severe OSA can have several interpretations. PTA reflects the function of the inner ear, specifically the hair cells. The outer hair cells function in amplifying the signal, while the inner hair cells function as a receptor. Hair cells of the organ of Corti react to sound frequencies according to their tonotopic arrangement; high frequency sounds are registered peripherally, specifically, at the base of the organ of Corti (Kinely and Zwolan 2010). This periphery is supplied by end arterioles without anastomoses, and thus may be more sensitive to fluctuations in oxygen than areas of the retina remote from the fovea centralis (Ficker et al. 1997, Nomura 1977).

In contrast to PTA, TEOAE was not able to localize which part of the organ of Corti may be dysfunctional, nor did it detect hearing impairment at the highest frequencies, as the acoustic click is uniform and contains a wide range of frequencies of up to $6000 \mathrm{~Hz}$ (Kemp 2002). Deterioration of hearing is dependent on age, is commonly known and is due to changes in the organ of Corti (Pearson et al. 1995, Popelar et al. 2006). This also corresponds with the results of the present study, where an association was shown between increased auditory threshold and decreased reproducibility of TEOAE with age. The absence of BAEP abnormalities in OSA indicates that the retrocochlear auditory pathway is not damaged. This 
result was expected given the richer blood supply, making the retrocochlear auditory pathway more resistant to inadequate blood supply or oxygen reduction than the organ of Corti (Bamiou 2015).

Assuming dysfunctional vascular supply (oxygen delivery), the lower part of the organ of Corti is implicated in the decreased perception of higher frequency sounds. Snoring has also been cited as a potential risk factor for hearing disorders as it represents noise load and vibrations (Pevernagie et al. 2010). However, we do not expect any impact in the present study as all patients had a history of snoring.

The limitations of the present study include the number patients examined and the absence of snoring intensity and frequency measurements, however this parameter has little value when it is measured only once. More extensive studies are needed to further elucidate the etiology of hearing impairment in OSA.

\section{Conclusion}

In the present study, we observed increased auditory threshold by PTA following auditory stimuli at frequencies of 4000 and $8000 \mathrm{~Hz}$ in males with severe OSA. This decreased auditory perception correlated with the severity of sleep apnea. TEOAE and BAEP results were not affected by OSA. Our results suggest a selective hearing pathway impairment at the base of the organ of Corti in severe OSA.

\section{Conflict of Interest}

There is no conflict of interest.

\section{Acknowledgements}

The authors are grateful to the staff of the Department of Neurology Sleep and Wake Disorders Centre, First Faculty of Medicine, Charles University and General Faculty Hospital in Prague, as well as to Veronika Krejci, M.D., for assistance with ultrasound examination of carotid arteries, and to Olga Kučerová, registered nurse, for the registration of BAEP examinations. The present work was supported by Charles University grant PRVOUK P26/LF1/4.

\section{References}

BAMIOU DE: Hearing disorders in stroke. In: Handbook of Clinical Neurology Vol. 129. AMINOFF MJ, BOLLER F, SWAAB DF (eds), Elsevier, Amsterdam, Netherlands, 2015, pp 633-637.

CANESSA N, CASTRONOVO V, CAPPA SF, ALOIA MS, MARELLI S, FALINI A, FERINI-STRAMBI L: Obstructive sleep apnea: brain structural changes and neurocognitive function before and after treatment. $A m J$ Respir Crit Care Med 183: 1419-1426, 2011.

CASALE M, VESPERINI E, POTENA M, PAPPACENA M, BRESSI F, BAPTISTA PJ, SALVINELLI F: Is obstructive sleep apnea syndrome a risk factor for auditory pathway? Sleep Breath 16: 413-417, 2012.

CIMINO A, SPECIALE R, GALliNA S, CIMINO M, CHILlURA M, LO PRESTI GM, CIULLA L: Brain stem auditory evoked potentials in obstructive sleep apnea syndrome (in Italian). Acta Otorhinolaryngol Ital 15: 15-17, 1995.

DRAGER LF, GENTA PR, PEDROSA RP, NERBASS FB, GONZAGA CC, KRIEGER EM, LORENZI-FILHO G: Characteristics and predictors of obstructive sleep apnea in patients with systemic hypertension. Am J Cardiol 105: 1135-1139, 2010.

DUMITRASCU R, TIEDE H, ECKERMANN J, MAYER K, REICHENBERGER F, GHOFRANI HA, SEEGER W, HEITMANN J, SCHULZ R: Sleep apnea in precapillary pulmonary hypertension. Sleep Med 14: 247-251, 2013.

EVANS AB: Clinical Utility of Evoked Potentials: Brainstem Auditory Evoked Potentials [online] Medscape, 2012. $<$ http://emedicine.medscape.com/article/1137451-overview\#aw2aab6b4>

FICKER JH, FEISTEL H, MOLLER C, MERKL M, DERTINGER S, SIEGFRIED W, HAHN EG: Changes in regional CNS perfusion in obstructive sleep apnea syndrome: initial SPECT studies with injected nocturnal 99mTc-HMPAO (in German). Pneumologie 51: 926-930, 1997.

GAMI AS, OLSON EJ, SHEN WK, WRIGHT RS, BALLMAN KV, HODGE DO, HERGES RM, HOWARD DE, SOMERS VK: Obstructive sleep apnea and the risk of sudden cardiac death: a longitudinal study of 10,701 adults. J Am Coll Cardiol 62: 610-616, 2013. 
GILAT H, VINKER S, BUDA I, SOUDRY E, SHANI M, BACHAR G: Obstructive sleep apnea and cardiovascular comorbidities: a large epidemiologic study. Medicine 93: e45, 2014.

HWANG JH, CHEN JC, HSU CJ, LIU TC: Association of obstructive sleep apnea and auditory dysfunctions in older subjects. Otolaryngol Head Neck Surg 144: 114-119, 2011.

ICSD-2 - International classification of sleep disorders, $2^{\text {nd }}$ edition. Diagnostic and Coding Manual. American Academy of Sleep Medicine, Westchester IL, 2005.

JECH R, RŮŽIČKA E: Brain stem auditory evoked potentials reflect central nervous system involvement in myasthenia gravis. J Neurol 243: 547-550, 1996.

KEMP DT: Otoacoustic emissions, their origin in cochlear function, and use. Br Med Bull 63: 223-241, 2002.

KEMP DT: Otoacoustic emissions and evoked potentials. In: The Oxford Handbook of Auditory Science: The Ear. FUCHS PA (ed.), OUP, Oxford, UK, 2010, pp 93-138.

KENDZERSKA T, GERSHON AS, HAWKER G, TOMLINSON G, LEUNG RS: Obstructive sleep apnea and incident diabetes. A historical cohort study. Am J Respir Crit Care Med 190: 218-225, 2014.

KINELY PR, ZWOLAN TA: Diagnostic audiology. In: Otolaryngology: Head \& Neck Surgery. 5th ed. CUMMINGS CW, FLINT PW, HAUGHEY BH (eds), Mosby Elsevier, Philadelphia, USA, 2010, pp 1887-1904.

KOTTERBA S, RASCHE K: Acoustic evoked potentials (AEP) in obstructive sleep apnea syndrome (in German). Pneumologie 50: 924-926, 1996.

MANIN G, PONS A, BALTZINGER P, MOREAU F, IAMANDI C, WILHELM JM, LENOBLE P, KESSLER L, KESSLER R: Obstructive sleep apnoea in people with type 1 diabetes: prevalence and association with microand macrovascular complications. Diabet Med 32: 90-96, 2015.

MARIN JM, CARRIZO SJ, VICENTE E, AGUSTI AG: Long-term cardiovascular outcomes in men with obstructive sleep apnoea-hypopnoea with or without treatment with continuous positive airway pressure: an observational study. Lancet 365: 1046-1053, 2005.

MATHERS C, SMITH A, CONCHA M: Global burden of hearing loss in the year 2000. Global Burden of Disease 18: $1-30,2000$.

MCFADDEN D: A speculation about the parallel ear asymmetries and sex differences in hearing sensitivity and otoacoustic emissions. Hear Res 68: 143-151, 1993.

MOSKO SS, PIERCE S, HOLOWACH J, SASSIN JF: Normal brain stem auditory evoked potentials recorded in sleep apneics during waking and as a function of arterial oxygen saturation during sleep. Electroencephalogr Clin Neurophysiol 51: 477-482, 1981.

NAMTVEDT SK, HISDAL J, RANDBY A, AGEWALL S, STRANDEN E, SOMERS VK, RØSJØ H, OMLAND T: Impaired endothelial function in persons with obstructive sleep apnoea: impact of obesity. Heart 99: 30-34, 2013.

NOMURA Y: Vascular supply to the organ of Corti in man. Arch Otorhinolaryngol 214: 213-220, 1977.

PAQUEREAU J, MEURICE JC, NEAU JP, INGRAND P, PATTE F: Auditory brainstem responses (ABRs) in sleep respiratory disorders. Eur J Clin Invest 24: 156-160, 1994.

PEARSON JD, MORRELL CH, GORDON SALANT S, BRANT LJ, METTER EJ, KLEIN LL, FOZARD JL: Gender differences in a longitudinal study of age associated hearing loss. J Acoust Soc Am 97: 1196-1205, 1995.

PEVERNAGIE D, AARTS RM, DE MEYER M: The acoustics of snoring. Sleep Med Rev 14: 131-144, 2010.

POPELAR J, GROH D, PELÁNOVÁ J, CANLON B, SYKA J: Age-related changes in cochlear and brainstem auditory functions in Fischer 344 rats. Neurobiol Aging 27: 490-500, 2006.

RECHTSCHAFFEN A, KALES A: A Manual of Standardized Terminology, Techniques and Scoring System for Sleep Stages of Human Subjects. RECHTSCHAFFEN A, KALES A (eds), Brain Information Service - Brain Research Institute, Los Angeles, USA, 1968.

REICHENBACH T, STEFANOVIC A, NIN F, HUDSPETH AJ: Waves on Reissner's membrane: a mechanism for the propagation of otoacoustic emissions from the cochlea. Cell Rep 1: 374-384, 2012.

ROBINETTE MS, GLATTKE TJ: Transient evoked otoacoustic emissions. In: Otoacoustic Emission, Clinical Applications. ROBINETTE MS, GLATTKE TJ (eds), Thieme, New York, USA, 2002, pp 95-116.

SCHLEGEL J, URBAN PP: Electrophysiological brain-stem diagnosis in patients with a pronounced obstructive sleep apnea syndrome (in German). Dtsch Med Wochenschr 124: 613-617, 1999. 
ŠKODA O, BAR M, ŠKOLOUDÍK D: Duplex sonography of extracranial arteries - a national standards assessment in the framework of functional specialization in neurosonology (in Czech). Cesk Slov Neurol Neurochir 65/98 (Suppl 2): 5-8, 2002.

TORELLI F, MOSCUFO N, GARREFFA G, PLACIDI F, ROMIGI A, ZANNINO S, BOZZALI M, FASANO F, GIULIETTI G, DJONLAGIC I, MALHOTRA A, MARCIANI MG, GUTTMANN CR: Cognitive profile and brain morphological changes in obstructive sleep apnea. Neuroimage 54: 787-793, 2011.

URBAN PP, SCHLEGEL J, ELLRICH J, KOEHLER J, HOPF HC: Electrophysiological brainstem investigations in obstructive sleep apnoea syndrome. J Neurol 243: 171-174, 1996.

ZUCCONI M, FERRI R, ALLEN R, BAIER PC, BRUNI O, CHOKROVERTY S, FERINI-STRAMBI L, FULDA S, GARCIA-BORREGUERO D, HENING WA, HIRSHKOWITZ M, HÖGL B, HORNYAK M, KING M, MONTAGNA P, PARRINO L, PLAZZI G, TERZANO MG; INTERNATIONAL RESTLESS LEGS SYNDROME STUDY GROUP (IRLSSG): The official World Association of Sleep Medicine (WASM) standards for recording and scoring periodic leg movements in sleep (PLMS) and wakefulness (PLMW) developed in collaboration with a task force from the International Restless Legs Syndrome Study Group (IRLSSG). Sleep Med 7: 175-183, 2006. 